\title{
Wayfinding Systems: Digital Versus Analogical Media
}

\author{
Maria Luisa Costa ${ }^{1,2(\bowtie)}$ \\ ${ }^{1}$ CIAUD, Faculdade de Arquitetura da Universidade de Lisboa, Rua Sá \\ Nogueira, Pólo Universitário, Alto da Ajuda, 1349-063 Lisbon, Portugal \\ design.luisacosta@gmail.com \\ 2 Instituto Superior Miguel Torga, Largo da Cruz de Celas n ${ }^{\circ} 1$, \\ Coimbra, Portugal
}

\begin{abstract}
In today's society space is overloaded with visual information, thus digital platforms are being increasingly used in design and could contribute to hinder this trend, assuming digital media and mobile platforms as an alternative to analogical media (paper support). In what concerns wayfinding systems, they need to allow more then to reach a point, starting from another, they should allow the experience and the knowledge of space, by allowing several layers of information, that people can use or not, depending on their interests and ambitions. This paper presents a study about the preferences and difficulties of people over 50 years old in the use of analogical and digital maps and discusses the possibility of the use of wayfinding systems in digital means for this age group, regarding the Design principles and inclusivity.
\end{abstract}

Keywords: Design $\cdot$ Wayfinding systems $\cdot$ Digital $\cdot$ Analog $\cdot$ Inclusivity

\section{Introduction}

Nowadays, accessing the city and different social or cultural spaces is an arduous task due to increasing territorial complexity, population growth, proliferation of visual information that "inhabits" the territory, and above all the fact that the city to assume, according to Acher [1], as an immense palimpsest that does not change and successively receives different writings.

Cities are growing and, according to UN data UN [2], it appears that since 2008, more than half of the world population has lived in cities. In parallel with the growth of cities and according to data from the National Statistics Institute [3] in Portugal, there is a progressive aging of the population, and it is expected that in 2031, of the 7.5 million inhabitants, 2.8 million will be elderly. This situation leads Designers to consider the need to design while taking care of the needs of an aging population.

The need to use wayfinding systems increases in direct proportion to the growth of cities and in technological potential. Wayfinding systems should respond to the needs of the population, in some cases with objective, clear and unambiguous information on the fastest way to reach a certain point, as is the case with transport interfaces, garages, airports, hospitals, etc. In other cases, when the movement is driven by leisure, and particularly in the context of cultural itineraries, these systems must allow individuals 
to enjoy the space more fully, create their own experiences and, through access to multiple information, expand knowledge. The design task is often to build tools and systems through which others can create their own experiences [4].

This paper reflects about individuals who are above 50 age and have not grown in contact with technologies, which today are an integral part of our daily lives. In this sense, and due to the importance, that maps assume in the context of wayfinding systems, and the increasing use of digital maps, we developed a questionnaire where we evaluated the use of digital and paper maps by individuals above 50. We questioned the difficulties and preferences and assessed the existence of differences between genders and academic levels.

\section{Designing the City}

Designers actively participate in the construction of the visual universe of cities, through informational messages such as signs and toponymy but also through advertising. According to the Design Manifesto [5], competence and creativity, as well as the activity of designers, have been directed towards promoting consumption, and designers use their time and energy in the creation and development of products that, after all, are superfluous. This practice needs to be reversed, and designers must direct projects towards the common good, bettering the lives of citizens. In the present case, we are concerned with improving accessibility in the context of the city, in order to make them more inclusive and adapted to contemporary social realities.

According to UN data [2], the number of individuals living in cities is expected to double from 3,300 million in 2007 to 6,400 million in 2050. In addition to this, a high number of individuals living outside the city travel there to access goods and services and, also, tourist flows supported by the current ease of travel, by the improvement of social conditions and the growing cultural interest which the widespread access to information enhances, as well as the free time older generations have to dedicate themselves to leisure and knowledge.

The forms of urbanity produced by design projects and developed in the city space are elements of communication that promote meaning and sense [6].

In order to read the city according to Lynch [7], the clues and signs that enable recognition and orientation are decisive and the greater this legibility is, the greater the comfort and well-being of citizens. However, there is an increase in territorial complexity, where natural images, such as buildings, streets and landscapes, which would assist in the reading of the city, overlap multiple images produced, resulting mainly from advertising. Both live together and accumulate in multiple layers in the public space. From this growing complexity and multiplication of images, reading the city's structural elements becomes very difficult, making it necessary to expand the auxiliary means of reading it, especially when citizens move outside their "comfort space" in the residence or work area.

The city can be interpreted as a picture of mental and symbolic maps that reflect a different way of appropriating the same space depending on the presence of individuals and the relationships between them [8]. 
Moving around and accessing different places with tranquility and security, without feeling disoriented is very important for all citizens, which will contribute to establishing a harmonious relationship between you and the outside world. This is the reverse of the fear that derives from disorientation; it means that the sweet sense of home is the strongest when the home is not only familiar, but also distinctive [7]. In this sense, the wayfinding systems can contribute to an easier circulation around the city, promoting a sense of security and well-being, especially among the elderly.

\section{Inclusive Design and Aging}

In view of the aging process, individuals lose their physical, sensory and/or cognitive capacities, considering that the increase in life expectancy that results from this demographic implies that individuals, once released from family and professional commitments, have more time to devote to hobbies, to move and to travel. We know that the complex, confusing and crowded city is full of barriers that limit accessibility and these are not exclusively physical, many derive from the impossibility of reading the city and the recognition of geographical space and make safe travel impossible. Most of the barriers that prevent many citizens from engaging in democratic life, and limit the full exercise of active citizenship, are designed and built by men [9].

Inclusive design, also known as Universal design is an approach to creating environments and products that are usable by all people to the greatest extent possible [10], placing emphasis on identifying as many needs as possible, across all potential users. Considering the physical, cognitive and emotional changes, as well as the social changes that individuals experience throughout life [10].

The need to safeguard accessibility and inclusiveness has long been an objective of design and the focus on older groups is becoming increasingly necessary in the face of demographic aging. As in many other countries, in Portugal the population is expected to decline, from 10.3 million to 7.5 million in 2031 , while the number of elderly people will increase from 2.1 to 2.8 million [3].

The WHO defines that the age groups of the elderly should be conceptualized according to the socio-cultural and economic-political characteristics of the countries [11]. In the European Union, it is consensual to consider elderly people over 65 years of age, in accordance with retirement standards. The United Nations argues that older people are all people over 60 years of age. In Africa it is consensual to define that the elderly are people over 50 years of age [12].

In fact, the classification of elderly people is defined according to what is indicated by the WHO, but we must consider that the aging process is not homogeneous and chronological age is not the best indicator of the individual process [13]. The reality is the entire multicellular organism undergoes physiological changes over time, with aging being characterized by a decline in the functional capacity of the organism [14].

However, it is a mistake to think of the older user as a wheelchair user or as severely disable. Older users are that vast number of people who, in advancing age have a little discernible impairment, but have a strong drive to remain independent and to contribute to the community, but are hampered by inappropriate design. Better design can play a crucial role in enabling older people to remain active [15]. 
Only above 75 , the visual acuity becomes a problem, namely the difficulty in reading signs, they are more dependent on high contrast between sign backgrounds and lettering; a reduced capacity for sensory processing or problem solving can increase difficulties in older adults when negotiating unfamiliar environments; the reduced manual dexterity and coordination can affect their ability to operate common mechanisms such as phones [16].

According to Boch and Gharaveis [17], we defend that humans privilege independence, whether they move around the house or take a long trip. The lack of confidence in their navigational skills can reduce their desire to travel, so wayfinding projects aimed at an older population should take care of these needs and constraints.

\section{Wayfinding Systems}

Wayfinding systems facilitate access to places that individuals are not familiar with, allowing a set of information that, depending on the space in question, may include landmarks, signage and maps.

The wayfinder is an individual who travels on foot or by bicycle with the aim of finding a specific place [18]. According to this definition, we are all wayfinders. Assuming navigation issues are an essential activity in our lives. Recently, many people use smartphones for outdoor navigation in the city, or indoor in hospitals, museums and others. With the success of smartphones, outdoor and indoor navigation systems for pedestrians have reached the end consumer market [19].

The trend of population aging in contemporary societies determines measures implemented regarding inclusiveness [8]. The main means used in wayfinding systems usually consist of maps and signal systems, symbols, colors and typography that indicate the direction of individuals. Progressively these means integrate mobile applications and automatic identification systems, paving the way for new approaches in wayfinding systems [6]. Currently, maps continue to be an integral and necessary part of wayfinding systems, with digital maps becoming increasingly important, but when designing a wayfinding system, we can use these means without risk of exclusion of individuals over 50. This is the answer to which we seek to respond.

\section{Method}

This paper aims to analyze how people over 50 use printed and digital maps. We were interested in this age group because they did not grow up with technology and we want to understand if despite this, they improved their knowledge in this matter and if they are able to use digital platforms without important restraints.

For this, the first part of the survey creates a small socio-demographic framework, in order to obtain information on participants' gender, age, level of education and work. The second part, surveys the subjects on their preferences and difficulties using digital and analogical media. 
The questionnaire consists of multiple choice answers, short answers and a set of open ended questions that allow us to obtain more information that we didn't have thought yet, none of the questions was mandatory.

The Google Forms platform was used to carry out the questionnaire and was disseminated through email lists, and Facebook social network.

This study involved 94 participants, women $(n=64)$ and men $(n=30)$, the ages of respondents ranged from 51 to $80(\mathrm{M}=61.3)$.

Regarding academic level, 76 respondents have higher education, 18 middle or professional education, and no responses from individuals with basic education.

\section{Results and Discussion}

With regard to the total number of people moving to unknown places, 62 claims to use paper maps (66\%) and 79 digital maps (93\%) (Tables 1, 2 and 3).

Table 1. Use of paper and digital maps for frequent and rare trips to unknown places.

\begin{tabular}{l|l|l}
\hline Frequent trips & Paper maps & Digital maps \\
\hline Use & $48(67 \%)$ & $62(94 \%)$ \\
\hline Do not use & 24 & 4 \\
\hline Rare trips & Paper maps & Digital maps \\
\hline Use & $14(64 \%)$ & $17(89 \%)$ \\
\hline Do not use & 8 & 2 \\
\hline
\end{tabular}

Table 2. Use of paper and digital maps - by gender

\begin{tabular}{l|l|l|l|l}
\hline \multirow{2}{*}{ Use of maps - by gender } & \multicolumn{2}{|l|}{ Paper maps } & \multicolumn{2}{l}{ Digital maps } \\
\cline { 2 - 5 } & Use & Do not use & Use & Do not use \\
\hline Masculine & $24(80 \%)$ & 6 & $23(92 \%)$ & 2 \\
\hline Feminine & $38(59 \%)$ & 26 & $56(93 \%)$ & 4 \\
\hline
\end{tabular}

Table 3. Use of paper and digital maps - by academic level

\begin{tabular}{l|l|l|l|l}
\hline Use of maps - by academic level & \multicolumn{2}{|l|}{ Paper maps } & \multicolumn{2}{l}{ Digital maps } \\
\cline { 2 - 5 } & Use & Do not use & Use & Do not use \\
\hline Middle or professional school & $14(78 \%)$ & 4 & $12(86 \%)$ & 2 \\
\hline University & $48(63 \%)$ & 28 & $67(94 \%)$ & 4 \\
\hline
\end{tabular}

Regarding the use of paper maps, of the 32 respondents who stated they no longer use paper maps, 26 justify replacing them with digital maps due to their accessibility and reliability of information; 2 justify it due to the fact that paper maps become outdated very quickly, 1 answer refers to problems with the handling of these maps. 
When asked about the reasons for continuing to use paper maps, 10 responses mention there is no need for an internet connection, nor dependence on the battery of electronic equipment; 11 respondents report that paper maps provide more comprehensive or global view of space; 2 respondents highlight the complementary use of analog and digital maps; while another 2 answers mention the advantage of being able to write and take notes on these maps.

Regard to digital maps, 8 respondents indicate that these maps are very practical, accurate and up-to-date; 2 responses refer to the importance of digital maps in reducing the use of paper and printing ink; the possibility of obtaining geographic information at various scales and varying them during the consultation, was 1 of the responses obtained; 3 responses mention the fact that it is possible to access information on exact distances (meters or $\mathrm{kms}$ ), information on travel time and directions to follow; there is also 1 answer that refers the possibility of exploring the route until the destination point.

Regarding the answers given to specific questions previously identified by us and classified on a scale from 0 (without difficulty) to 5 (maximum difficulty), with regard to paper maps, the difficulties related to legibility are particularly relevant, due to the size of letter $(M=3.3)$ and use of color or chromatic contrast $(M=2.9)$. As positive aspects (0 nothing to 5 very much), affection and personal taste for paper maps $(\mathrm{M}=3.0)$, as well as the fact that printed maps are part of the memories that individuals like to bring $(\mathrm{M}=3.0)$.

Regarding the use of digital maps, internet access difficulties are referred $(\mathrm{M}=3.0)$, about this aspect, it is worth noting that $14 \%$ of respondents only use free wi-fi. Regarding the positive aspects in the use of digital maps, it refers to the functionality within the scope of the trip preparation $(\mathrm{M}=3.6)$, as well as the possibility of accessing more information in addition to the exclusively geographical $(M=3.8)$.

\section{Conclusions}

The results of this study reveal the use and difficulties experienced by individuals over 50 in the use of analog and digital maps. We consider that it may be a limitation of this survey the lack of answers given by individuals with basic education. The sample presents results based on individuals with above-average academic training in Portugal, which may mean that the results cannot be applied in all contexts.

The data obtained allow us to verify that, in the age groups above 50, both analog and digital maps are used simultaneously and in complementarity, $66 \%$ of individuals claim to use paper maps and $93 \%$ use digital maps, a percentage that allows us to conclude that the use of digital maps is not an obstacle for these age groups, having been mentioned by 26 , of the 32 individuals who stopped using paper maps, that replaced them by digital ones because they are more reliable and are updated. Advantages are also mentioned in the use of digital maps in the preparation of the trip and exploration of the routes.

Regarding the difficulties in the use of digital maps, issues related to the capabilities of the equipment (mobile phones and batteries) and internet access are mentioned, considering the respondents that the platforms are very intuitive and easy to use. 
With regard to paper maps, handling and legibility are indicated as the main difficulties, with benefits being the possibility of a broader view of space, as well as factors related to an emotional connection to maps as objects that one likes and wants to bring as a souvenir.

About the analysis of the use of digital maps by gender, there are no significant differences between the female and male universe, whereas with regard to the use of paper maps there is a greater use by men $(80 \%)$ than by women $(59 \%)$.

Concerning academic levels, it can be verified a larger percentage of digital maps use by individual with university education ( $94 \%)$, than by those with middle school level $(86 \%)$. The situation is reversed with paper maps: less use by individuals with university education $(63 \%)$ than by those with middle school education $(78 \%)$.

By crossing results obtained, revised literature and direct observation, we can conclude that is possible and desirable the integration of digital maps in wayfinding systems, namely those for cultural itineraries, without excluding people over 50, making it possible to use and enjoy all the possibilities that technologies offer, by implementing different playful and informative layers. However, we consider that it should not be overlooked the importance that paper maps still have for these age groups, and they should present a macro vision of the territory and fulfill their role as a 'trophy' and souvenir in the context of a trip.

\section{References}

1. Archer, F.: Novos princípios do urbanismo, seguido de novos compromissos urbanos - um léxico. Livros Horizonte, Lisboa (2010)

2. United Nations: World Population Prospects: The 2015 Revision, Key Findings and Advance Tables (2015)

3. National Institute of Statistics (2017). http://www.ine.pt

4. AIGA Design Futures. https://www.aiga.org/aiga-design-futures/complex-problems

5. First Things First: A Design Manifesto. AIGA J. (2000). http://www.xs4all.nl/ maxb/ ftf2000.htm

6. Costa, M.L., Amaral, I.: Communication design and space narratives. In: Raposo, D., Neves, J., Silva, J. (eds.) Perspective on Design. Springer Series in Design and Innovation, vol. 1. Springer, Cham (2020)

7. Lynch, K.: A Imagem da Cidade. Edições 70, Lisboa (1960)

8. Costa, M.L., Amaral, I., Daniel, F.: The contribution of information design to age-friendly cities: a case study on Coimbra and public transport. In: Rebelo, F., Soares, M.M. (eds.) AHFE 2018, AISC 777, pp. 485-496. Springer International Publishing AG, Berlin (2018)

9. Simões, J.F., Bispo, R.: Design Inclusivo: acessibilidade e usabilidade em produtos, serviços e ambientes. Centro Português de Design (2006)

10. Beneficial Designs: Designing sidewalks and trails for access, Part II - Best Practices Design Guide. Department of Transportation. Federal Highway Administration, USA (1999)

11. World Health Organization: Active Ageing: A policy Framework. World Health Organization, Geneva (2012)

12. Costa, M.L., Amaral, I.: Cidades e Sistemas Wayfinding. Convergências - Revista de Investigação e Ensino das Artes, vol. XI, no. 21 (2018)

13. Marques, S.: Discriminação da Terceira Idade. FFMS and Relógio D’Água Editores, Lisboa (2011) 
14. Hoffmann, M.E.: Bases biológicas do envelhecimento. Idade Ativa-Revista Eletrônica da Terceira Idade (2003)

15. Huppert, F.: Designing for older users. In: Coleman, R., Lebon, C., Clarkson, J., Keates, S. (eds.) Inclusive Design: Design for the Whole Population, pp. 30-49. Springer, London (2003)

16. Beneficial Designs: Designing sidewalks and trails for access, Part I - Review of Existing Guidelines and Practices. Department of Transportation, Federal Highway Administration, USA (1999)

17. Boch, S.J., Gharaveis, A.: Flying solo: a review of the literature on wayfinding for older adults experiencing visual or cognitive decline. Applied Ergonomics 58, 327-333 (2017)

18. Mollerup, P.: Wayshowing: A Guide to Environmental Signage. Lars Muller Publishers, Baden (2005)

19. Rodriguez-Sanchez, M.C., Martinez-Romo, J.: GAWA-manager for accessibility wayfinding apps. Int. J. Inf. Manag. 37, 505-519 (2017) 